\title{
Documentation of inherited knowledge on wild edible fungi from Malaysia
}

\begin{abstract}
The gradual loss in traditional knowledge on wild edible fungi is a common phenomenon the world over, including Malaysia. A documentation of known edible fungi in Malaysia was executed, with the objective of salvaging traditional knowledge on the identification and edibility of these mushrooms, particularly from her village communities. Among those that have been successfully documented in this study were Cookeina and Galiella of the class Ascomycetes and Termitomyces, Schizophyllum, Hygrocybe, Lentinus, Calvatia, Calostoma and Auricularia, from the Basidiomycetes which make up a total of 13 or 14 species belonging to 9 genera. It is hoped that this documentation will contribute towards an updated scientific identification, including their genetic sequences in the near future.
\end{abstract}

Keyword: Malaysia; Wild edible fungi 